NBER WORKING PAPER SERIES

\title{
RATIONAL-EXPECTATIONS EQUILIBRIUM IN INTERMEDIATE GOOD MARKETS
}

\author{
Robert S. Gibbons \\ Richard T. Holden \\ Michael L. Powell \\ Working Paper 15783 \\ http://www.nber.org/papers/w15783 \\ NATIONAL BUREAU OF ECONOMIC RESEARCH \\ 1050 Massachusetts Avenue \\ Cambridge, MA 02138 \\ February 2010
}

The views expressed herein are those of the authors and do not necessarily reflect the views of the National Bureau of Economic Research.

NBER working papers are circulated for discussion and comment purposes. They have not been peerreviewed or been subject to the review by the NBER Board of Directors that accompanies official NBER publications.

(C) 2010 by Robert S. Gibbons, Richard T. Holden, and Michael L. Powell. All rights reserved. Short sections of text, not to exceed two paragraphs, may be quoted without explicit permission provided that full credit, including $(\mathcal{C}$ notice, is given to the source. 
Rational-Expectations Equilibrium in Intermediate Good Markets

Robert S. Gibbons, Richard T. Holden, and Michael L. Powell

NBER Working Paper No. 15783

February 2010

JEL No. D80,G10

\begin{abstract}
$\underline{\text { ABSTRACT }}$
We analyze a rational-expectations model of information acquisition and price formation in an intermediategood market: prices and net supply are non-negative, there are no noise traders, and the intermediate good has multiple potential uses. Several of our results differ from the classic Grossman-Stiglitz approach. For example, the price mechanism is more informative at high and low prices and potentially uninformative at middle prices. Also, an informed trade by a producer of one final good amounts to a noise trade from the perspective of a producer of another final good, so (a) as the price mechanism becomes more informative for producers of one final good, it becomes less informative for producers of others, who therefore have a stronger incentive to acquire information, so information acquisition has the strategic-complements property between groups, and (b) having more producers (in multiple groups) become informed need not increase the informativeness of the price mechanism.
\end{abstract}

Robert S. Gibbons

Sloan School of Management

E52-432

MIT

Cambridge, MA 02142

and NBER

rgibbons@mit.edu

Richard T. Holden

University of Chicago

Booth School of Business

Room 528

5807 S Woodlawn Ave

Chicago,IL 60637

and NBER

richard.holden@chicagobooth.edu
Michael L. Powell

MIT

mlp@mit.edu 


\section{Introduction}

Since at least Hayek (1945), economists have understood that "We must look at the price system as... a mechanism for communicating information if we want to understand its real function" (p. 526). Beginning in the 1970s, Grossman (1977) and Grossman and Stiglitz (1976, 1980) developed formal models analyzing this issue. In these classic models, some market participants make a costly investment in becoming informed about the value of an asset; others do not, but make rational inferences from the equilibrium price. The analysis is intricate, because the price plays two roles: informing uninformed parties about the asset's value, but also clearing the market. This dual role for the price requires computation of the price function as a fixed point, and closed-form solutions are typically not available. One special case that does admit closed-form solutions is when agents have exponential utility functions and all random variables are jointly normally distributed. ${ }^{1}$

Many of these models of rational-expectations equilibrium seem best suited as (and are often intended to be) models of financial markets, as opposed to intermediate-good markets, in at least three senses. First, models that assume normal distributions allow prices and quantities to be negative, which may occur through short-selling and other practices in some financial markets, but seem unfamiliar in most intermediate-good markets (where free disposal keeps prices positive and the asset being a physical good keeps quantities positive). Second, in financial markets, the value of an asset today is tied to its fundamental value later, and this value is often the same for everyone. By definition, however, intermediate goods are used to produce something else and hence can have different values to producers seeking to produce different final goods.

Finally, with few exceptions (e.g., Ausubel (1990)), the rational-expectations literature has made use of a separate class of traders who buy or sell assets based on idiosyncratic shocks. According to Black (1986: pp 4-5), the noise these traders provide "makes financial

\footnotetext{
${ }^{1}$ Examples include: Grossman (1976), Grossman and Stiglitz (1980), Hellwig (1980), Verrecchia (1982), Admati (1985), Wang (1993), Veldkamp (2006), Yang and Ganguli (2008).
} 
markets possible" and provides incentives "for people to seek out costly information which they will trade on." Formally, such noise traders ensure that an uninformed trader cannot perfectly learn the value of an asset simply by observing the market-clearing price. In an intermediate-good market, however, where different classes of producers seek to produce different final goods, noise traders are no longer needed: now, an informed trade by a producer of one final good amounts to a noise trade from the perspective of a producer of another final good.

In this paper, we construct a rational-expectations model of information acquisition and price formation in the market for an intermediate good that can be used to produce two final goods. We assume that the values that consumers place on these final goods are uniformly distributed with positive supports, which allows us to ensure that prices and quantities in the intermediate-good market are always positive.

The main technical difficulty in our analysis is that, unlike in Grossman and Stiglitz (hereafter GS), the equilibrium price function is not linear. We show, however, that the price function is piecewise-linear over three regions of the parameter space. These three regions emerge naturally from our assumption of uniform distributions on the values of final goods, because uninformed producers' conditional belief about the value of their final good given the market price takes one of three forms: an upper tail of the prior distribution of finalgood values, a lower tail, or the entire support of possible values. Unlike GS, therefore, we find that the informativeness of the price mechanism depends on the realization of the price. In particular, the price mechanism is more informative at higher and lower prices (converging to perfectly informative at the maximum and minimum prices), but potentially completely uninformative in a middle range of prices. This piece-wise linearity allows us to obtain an explicit solution for the price function, which allows us to perform comparative-statics exercises, including revisiting the seven conjectures from Grossman and Stiglitz (1980).

The existence of two classes of producers, each seeking to produce a different final good, plays an important role in our model. All else equal, if more producers of one final good 
become informed about the value of their output, then the intermediate-good price will become more sensitive to (and hence more informative about) this value. Other producers of this good will find prices to be a better signal about the value of their output and so will be less inclined to become informed. There are thus positive within-group informational externalities (i.e., information acquisition has the strategic-substitutes property within groups). However, as the intermediate-good price becomes more sensitive to the value of one final good, it necessarily becomes less sensitive to (and thus less informative about) the value of the other final good. Producers of this second final good will find the intermediate-good price to be a less useful signal, so they will be more inclined to become informed. There are thus negative cross-group informational externalities (i.e., information acquisition has the strategic-complements property between groups). Additionally, if there is an increase in the number of producers of both goods who become informed, the inferences that uninformed producers draw from prices may be unchanged, since the positive externalities and negative externalities may cancel out. Thus, more producers trading on information does not necessarily increase the informativeness of prices for either group.

Our interest in this model is both direct and indirect. That is, we are interested in the model not only as a rational-expectations model of price formation in intermediate-good markets, but also as a model to be embedded in a larger application. In particular, in a related paper [Gibbons, Holden, and Powell (2009)] we embed a simplified version of this paper's model of price formation in a model of firms' integration decisions. In this sense, building on the present paper allows us to expand the focus of the transaction-cost/propertyrights literature on the boundary of the firm (e.g., Williamson (1971), Klein, Crawford, and Alchian (1978), Grossman and Hart (1986)): rather than study the integration versus nonintegration decision of one dyad in isolation, in our related paper we analyze how the separate integration decisions of a market's worth of dyads interact through the informativeness of the market's pricing function.

The remainder of the paper is organized as follows. Section 2 states the problem. Section 
3 takes the information-acquisition decisions of the producers as given and establishes the existence of a piece-wise linear rational-expectations equilibrium price function. Section 4 analyzes the information-acquisition game, establishing the existence and uniqueness of an equilibrium. Section 5 revisits the seven conjectures of Grossman-Stiglitz (1980). Section 6 concludes.

\section{Statement of the Problem}

There is a unit mass of producers, indexed by $i \in[0,1]$. An intermediate good (a "widget") can be used to produce one of two final goods. A fixed mass $q$ are good-1 producers, and a fixed mass $1-q$ are good-2 producers. Each producer is endowed with $w_{i} \in\{0,1\}$ widgets, and the total aggregate endowment is fixed at $x \leq 1$. Without loss of generality, assume $w_{i}=1$ if $i \leq x$.

At some cost $c_{i}$, a good-1 producer can transform a widget into a unit of good 1 , and a good-2 producer can transform a widget into a unit of good 2. This transformation cost is drawn from a uniform distribution on support $[0, \bar{c}]$. Consumers' value for the good $j$ is uncertain, with $v^{j}$ uniformly distributed on $\left[\underline{v}^{j}, \bar{v}^{j}\right]$. As in Grossman-Stiglitz, producers can pay to become informed about the consumer value that is relevant for them. More precisely, before observing $c_{i}$, producer $i$ who produces good $j$ can pay $k_{i}$ to learn $v^{j}$ (without error). We assume $k_{i}$ to be uniformly distributed on $[0, \bar{k}]$.

Producers not endowed with a widget may purchase one in the intermediate-good market, and endowed producers may sell into the market. All the random variables in the model $\left(v^{1}, v^{2}, c_{i}, k_{i}\right)$ are independent of each other. Denote the market price for a widget as $p$. Producers not directly informed about the relevant $v^{j}$ (because they chose not to pay the cost $k_{i}$ ) make rational inferences about $v^{j}$ from the equilibrium price.

Equilibrium in the market for widgets is determined by the price that equates supply (from both informed and uninformed good-j producers whose production costs are sufficiently 
high) and demand (from both informed and uninformed good-j producers whose production costs are sufficiently low). If this price perfectly revealed $v^{j}$, there would be no incentive for any good-j producer to pay the cost $k_{i}$ of learning $v^{j}$, but then prices would be uninformative about $v^{j}$. To avoid this result, there must not be a one-to-one mapping between prices at $v^{j}$, but this is no problem, since from the perspective of good-j producers, the random demand of widgets by good-i producers is essentially noise.

\section{$2.1 \quad$ Timing}

To be more precise about the timing and assumptions, suppose there are five time periods. At the beginning of the first period ("information acquisition"), nature draws the value of good $1, v^{1}$, from $U\left[\underline{v}^{1}, \bar{v}^{1}\right]$, and the value of good $2, v^{2}$, from $U\left[\underline{v}^{2}, \bar{v}^{2}\right]$, both of which are unobserved by all producers. Producers, who know whether they are good-1 producers or good-2 producers, observe their private cost of becoming informed $k_{i} \sim U[0, \bar{k}]$ and decide whether or not to become informed. In the second period ("endowment"), producers learn their index $i$ and all players with $i \leq y$ are endowed with $w_{i}=1$ widgets.

In the third period ("price formation and trading"), producer $i$ observes $c_{i} \sim U[0, \bar{c}]$ and $\varphi_{i} \in\left\{\emptyset, v^{j}\right\}$, a signal about the value $v^{j}$ of the final good they can produce. Let $\varphi_{i}=\emptyset$ denote the uninformative signal that obtains if $k_{i}$ is not incurred in the first period and $\varphi_{i}=v^{j}$ the perfectly informative signal that a good-j producer obtains if $k_{i}$ is incurred. Let $s_{i}=\left(c_{i}, \varphi_{i}\right)$ be the vector of $i$ 's signals, which are her private information.

In the fourth period ("production"), if producer $i$ has a widget and is a good-j producer, she can transform the widget into $q_{i}^{j}=1$ units of good-j at cost $c_{i}$. If producer $i$ does not have a widget, then $q_{i}^{j}=0$.

In the fifth period ("sales and production"), good 1 sells at price $v^{1}$ and good 2 sells at 
price $v^{2}$. Gross payoffs of a good-j producer are determined as follows

$$
\pi_{i}^{j}\left(v, s_{i}, p\right)=\left\{\begin{array}{cc}
v^{j}-c_{i}-p+p w_{i} & \text { if transform widget into good-j } \\
p w_{i} & \text { if not }
\end{array}\right.
$$

so we can write $\pi_{i}^{j}\left(v, s_{i}, p\right)=\left(v^{j}-c_{i}-p\right) q_{i}+p w_{i}$.

\section{Rational-Expectations Equilibrium}

In this section, we take $\lambda_{1}$ and $\lambda_{2}$, respectively the fraction of good- 1 and good- 2 producers who are informed, as given. We solve for the price function $p_{\lambda}(\cdot, \cdot)$ that both clears the market and communicates information to uninformed producers. Informed good-j producers are willing to purchase (or keep) a widget and transform it into a final good $\left(q_{i}^{j}=1\right)$ if and only if $p+c_{i} \leq v^{j}$, so the largest value of $c_{i}$ at which an informed good-j producer is willing to buy a widget is $c_{I}^{j}(v, p)=v^{j}-p$. Analogously, uninformed good-j producers are willing to purchase (or keep) and transform a widget if and only if $p+c_{i} \leq E\left[v^{j} \mid p_{\lambda}(\cdot, \cdot)=p\right]$, so we have $c_{U}^{j}(p)=E\left[v^{j} \mid p_{\lambda}(\cdot, \cdot)=p\right]-p$. Total demand for each group is then given by

$$
\begin{aligned}
& D^{1}(v, p)=q \lambda_{1} \frac{c_{I}^{1}(v, p)}{\bar{c}}+q\left(1-\lambda_{1}\right) \frac{c_{U}^{1}(p)}{\bar{c}} \\
& D^{2}(v, p)=(1-q) \lambda_{2} \frac{c_{I}^{2}(v, p)}{\bar{c}}+(1-q)\left(1-\lambda_{2}\right) \frac{c_{U}^{2}(p)}{\bar{c}} .
\end{aligned}
$$

Market-clearing requires that in each state of the world $\left(v^{1}, v^{2}\right)$,

$$
x=D^{1}(v, p)+D^{2}(v, p)
$$

It is important to note that $0 \leq \frac{v^{j}-p}{\bar{c}} \leq 1$ and $0 \leq \frac{E\left[v^{j} \mid p\right]-p}{\bar{c}} \leq 1$ must hold for all $\left(v^{1}, v^{2}\right)$ and $p\left(v^{1}, v^{2}\right)$. These conditions ensure, respectively, that demands for the groups of informed and uninformed parties are never negative or greater than unity, which must 
hold since they are probabilities. Intuitively, this will depend on the differences between the relative sizes of the final-good markets, $q$, and the difference between the supports of the distribution of values $\bar{v}^{1}-\bar{v}^{2}$ and $\underline{v}^{1}-\underline{v}^{2}$ in a way that will be made precise later. If $\bar{v}^{2}>>\bar{v}^{1}, \underline{v}^{2}>>\underline{v}^{1}$ and $q$ is relatively small, then prices will always be high, because the intermediate good is very valuable for good-2 producers who are relatively large in the market. This will in turn price out the good-1 producers from the market. Throughout the derivation of prices, we will assume these conditions hold, and at the end, we will provide conditions under which they in fact do.

As in GS, computing the conditional expectations $E\left[v^{j} \mid p_{\lambda}(\cdot, \cdot)=p\right]$ requires knowing the price function $p_{\lambda}(\cdot, \cdot)$, not merely the realized price $p$.

Definition 1 Assume a fraction $\lambda_{1}$ and $\lambda_{2}$ of good-1 and good-2 producers, respectively, are informed. A rational-expectations equilibrium $(\boldsymbol{R E E})$ is a price function $p_{\lambda}(\cdot, \cdot)$ and a production allocation $\left\{q_{i}^{j *}\right\}_{i \in[0,1]}$ such that

1. $q_{i}^{j *} \in \operatorname{argmax}_{q_{i}^{j} \in\{0,1\}} E_{v^{1}, v^{2}}\left[\pi_{i}^{j}\left(v^{1}, v^{2}, p\right) \mid p_{\lambda}(\cdot, \cdot)=p, s_{i}\right]$ for all $i$, for $j=1,2$.

2. (1) holds for all $v^{1}, v^{2}$.

We now establish the existence of an REE by construction. The price function is a mapping $p:\left[\underline{v}^{1}, \bar{v}^{1}\right] \times\left[\underline{v}^{2}, \bar{v}^{2}\right] \rightarrow \mathbb{R}$. Solving (1) for $p$ gives us

$$
p=q \lambda_{1} v^{1}+(1-q) \lambda_{2} v^{2}+q\left(1-\lambda_{1}\right) E\left[v^{1} \mid p\right]+(1-q)\left(1-\lambda_{2}\right) E\left[v^{2} \mid p\right]-\bar{c} x
$$

The slope of the isoprice line is given by $\frac{d v^{2}}{d v^{1}}=-\left(\frac{d p}{d v^{1}} / \frac{d p}{d v^{2}}\right)=-\frac{q}{1-q} \frac{\lambda_{1}}{\lambda_{2}}$. Corresponding to 
the following diagrams, there are two situations.

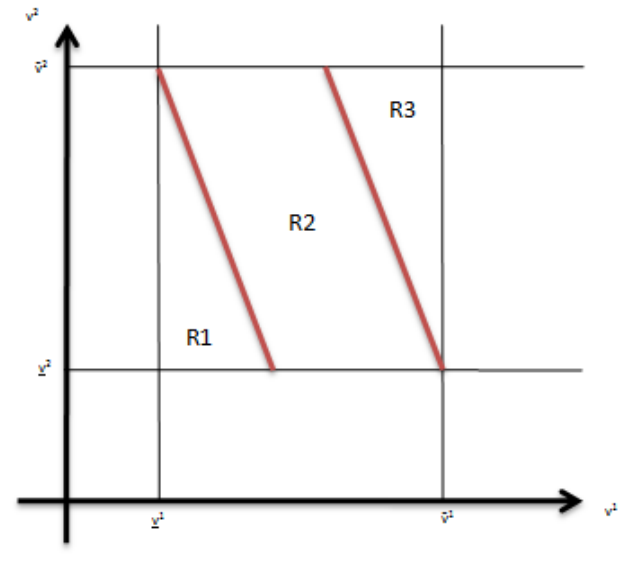

Case A

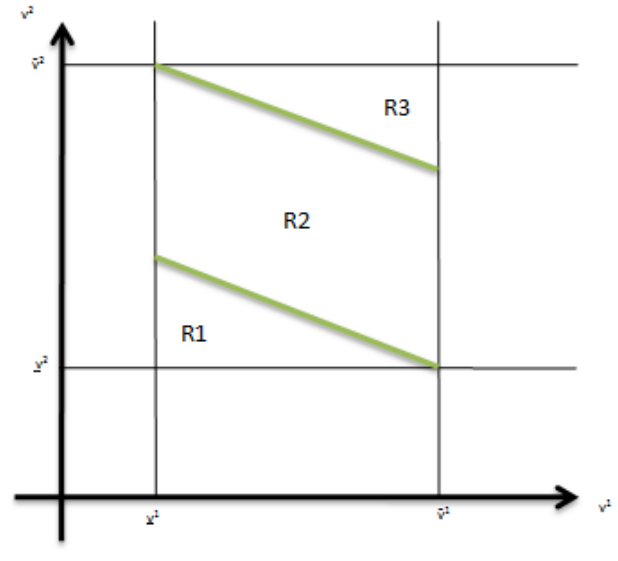

Case B

If the slope is greater than the slope of the diagonal (in absolute value), then we are in case A:

$$
\frac{q}{1-q} \frac{\lambda_{1}}{\lambda_{2}} \geq \frac{\bar{v}^{2}-\underline{v}^{2}}{\bar{v}^{1}-\underline{v}^{1}} .
$$

If the slope is less than the slope of the diagonal in absolute value, then we are in case B:

$$
\frac{q}{1-q} \frac{\lambda_{1}}{\lambda_{2}} \leq \frac{\bar{v}^{2}-\underline{v}^{2}}{\bar{v}^{1}-\underline{v}^{1}} .
$$

In case $\mathrm{A}$, prices are always more informative for good-1 producers than for good-2 producers. Indeed, in the middle region, prices are informative for good-1 producers and completely uninformative for good-2 producers. In case B, the opposite is true. We now turn to deriving the actual price function that obtains under Case A. The price function under Case B is stated in Proposition 1 and derived in the appendix. There are three 
regions:

$$
\begin{aligned}
& R_{\lambda}^{1}=\left\{\left(v^{1}, v^{2}\right): \underline{p} \leq p_{\lambda}\left(v^{1}, v^{2}\right) \leq p_{\lambda}\left(\underline{v}^{1}, \bar{v}^{2}\right)\right\} \\
& R_{\lambda}^{2}=\left\{\left(v^{1}, v^{2}\right): p_{\lambda}\left(\underline{v}^{1}, \bar{v}^{2}\right) \leq p_{\lambda}\left(v^{1}, v^{2}\right) \leq p_{\lambda}\left(\bar{v}^{1}, \underline{v}^{2}\right)\right\} \\
& R_{\lambda}^{3}=\left\{\left(v^{1}, v^{2}\right): p_{\lambda}\left(\bar{v}^{1}, \underline{v}^{2}\right) \leq p_{\lambda}\left(v^{1}, v^{2}\right) \leq \bar{p}\right\}
\end{aligned}
$$

We conjecture that there is a piecewise-linear price function

$$
\begin{aligned}
p_{\lambda}\left(v^{1}, v^{2}\right)= & 1_{\left\{(x, v) \in R_{\lambda}^{1}\right\}}\left[\beta_{0}^{1}+\beta_{1}^{1} v^{1}+\beta_{2}^{1} v^{2}\right]+1_{\left\{(x, v) \in R_{\lambda}^{2}\right\}}\left[\beta_{0}^{2}+\beta_{1}^{2} v^{1}+\beta_{2}^{2} v^{2}\right] \\
& +1_{\left\{(x, v) \in R_{\lambda}^{3}\right\}}\left[\beta_{0}^{3}+\beta_{1}^{3} v^{1}+\beta_{2}^{3} v^{2}\right] \\
= & 1_{\left\{(x, v) \in R_{\lambda}^{1}\right\}} p_{\lambda}^{1}\left(v^{1}, v^{2}\right)+1_{\left\{(x, v) \in R_{\lambda}^{2}\right\}} p_{\lambda}^{2}\left(v^{1}, v^{2}\right)+1_{\left\{(x, v) \in R_{\lambda}^{3}\right\}} p_{\lambda}^{3}\left(v^{1}, v^{2}\right),
\end{aligned}
$$

which is a fixed point of (1), rearranged in a more mathematically convenient way

$$
\begin{aligned}
& q\left(1-\lambda_{1}\right) E\left[v^{1} \mid p_{\lambda}(\cdot, \cdot)=p_{\lambda}\left(v^{1}, v^{2}\right)\right] \\
& +(1-q)\left(1-\lambda_{2}\right) E\left[v^{2} \mid p_{\lambda}(\cdot, \cdot)=p_{\lambda}\left(v^{1}, v^{2}\right)\right] \\
= & p+\bar{c} x-q \lambda_{1} v^{1}-(1-q) \lambda_{2} v^{2},
\end{aligned}
$$

and we seek to solve for the parameter vectors $\beta^{1}, \beta^{2}$, and $\beta^{3}$. To solve for $\beta^{1}$, assume $p \leq p_{\lambda}\left(\underline{v}^{1}, \bar{v}^{2}\right)$. Then individuals believe that

$$
\begin{aligned}
& v^{1} \mid p_{\lambda}(\cdot, \cdot)=p \sim U\left[\underline{v}^{1}(p), \bar{v}^{1}(p)\right] \\
& v^{2} \mid p_{\lambda}(\cdot, \cdot)=p \sim U\left[\underline{v}^{2}(p), \bar{v}^{2}(p)\right],
\end{aligned}
$$

where $\underline{v}^{j}(p)$ and $\bar{v}^{j}(p)$ are, respectively, the lowest and highest values of $v^{j}$ consistent with the realized price level. $\underline{v}^{j}(p)=\underline{v}^{j}$ and $\bar{v}^{1}(p)$ solves $p_{\lambda}^{1}\left(\bar{v}^{1}(p), \underline{v}^{2}\right)=p$ or

$$
\bar{v}^{1}(p)=\frac{1}{\beta_{1}^{1}}\left(p-\beta_{0}^{1}-\beta_{2}^{1} \underline{v}^{2}\right) .
$$


Given a price $p \leq p_{\lambda}\left(\underline{v}^{1}, \bar{v}^{2}\right)$, the conditional expectation of $v^{1}$ is then

$$
E\left[v^{1} \mid p\right]=\frac{\underline{v}^{1}(p)+\bar{v}^{1}(p)}{2}=\frac{\underline{v}^{1}+\left(p-\beta_{0}^{1}-\beta_{2}^{1} \underline{v}^{2}\right) / \beta_{1}^{1}}{2}
$$

Similarly, $\bar{v}^{2}(p)$ solves $p_{\lambda}^{2}\left(\underline{v}^{1}, \bar{v}^{2}(p)\right)=p$ or

$$
\bar{v}^{2}(p)=\frac{1}{\beta_{2}^{1}}\left(p-\beta_{0}^{1}-\beta_{1}^{1} \underline{v}^{1}\right) .
$$

The conditional expectation of $v^{2}$ is then

$$
E\left[v^{2} \mid p\right]=\frac{\underline{v}^{2}(p)+\bar{v}^{2}(p)}{2}=\frac{\underline{v}^{2}+\left(1 / \beta_{2}^{1}\right)\left(p-\beta_{0}^{1}-\beta_{1}^{1} \underline{v}^{1}\right)}{2} .
$$

Market clearing in (2) then requires

$$
\begin{aligned}
& q\left(1-\lambda_{1}\right) \frac{\underline{v}^{1}+\left(\left(\beta_{0}^{1}+\beta_{1}^{1} v^{1}+\beta_{2}^{1} v^{2}\right)-\beta_{0}^{1}-\beta_{2}^{1} \underline{v}^{2}\right) / \beta_{1}^{1}}{2} \\
& +(1-q)\left(1-\lambda_{2}\right) \frac{\underline{v}^{2}+\left(\left(\beta_{0}^{1}+\beta_{1}^{1} v^{1}+\beta_{2}^{1} v^{2}\right)-\beta_{0}^{1}-\beta_{1}^{1} \underline{v}^{1}\right) / \beta_{2}^{1}}{2} \\
\equiv & \left(\beta_{0}^{1}+\beta_{1}^{1} v^{1}+\beta_{2}^{1} v^{2}\right)+\bar{c} x-q \lambda_{1} v^{1}-(1-q) \lambda_{2} v^{2},
\end{aligned}
$$

where the equivalence relation reminds us that this holds as an identity in $\left(v^{1}, v^{2}\right)$. Rearranging and using equality of coefficients, we get

$$
\begin{aligned}
& \beta_{0}^{1}=\frac{q}{2}\left(\frac{\lambda_{2}-\lambda_{1}}{\lambda_{2}}\right) \underline{v}^{1}+\frac{(1-q)}{2}\left(\frac{\lambda_{1}-\lambda_{2}}{\lambda_{1}}\right) \underline{v}^{2}-\bar{c} x \\
& \beta_{1}^{1}=\frac{q}{2} \frac{\lambda_{1}+\lambda_{2}}{\lambda_{2}} \\
& \beta_{2}^{1}=\frac{1-q}{2} \frac{\lambda_{1}+\lambda_{2}}{\lambda_{1}}
\end{aligned}
$$

Similar calculations can be carried out for regions 2 and 3 , in which $p_{\lambda}\left(\underline{v}^{1}, \bar{v}^{2}\right)<p \leq$ 
$p_{\lambda}\left(\bar{v}^{1}, \underline{v}^{2}\right)$ and $p>p_{\lambda}\left(\bar{v}^{1}, \underline{v}^{2}\right)$, respectively, in which case we get

$$
\begin{aligned}
& p_{\lambda}^{1}\left(v^{1}, v^{2}\right)=\frac{q}{2}\left(\frac{\lambda_{2}-\lambda_{1}}{\lambda_{2}}\right) \underline{v}^{1}+\frac{1-q}{2}\left(\frac{\lambda_{1}-\lambda_{2}}{\lambda_{1}}\right) \underline{v}^{2}-\bar{c} x+\frac{q}{2} \frac{\lambda_{1}+\lambda_{2}}{\lambda_{2}} v^{1}+\frac{1-q}{2} \frac{\lambda_{1}+\lambda_{2}}{\lambda_{1}} v^{2} \\
& p_{\lambda}^{2}\left(v^{1}, v^{2}\right)=(1-q)\left(\frac{\lambda_{1}-\lambda_{2}}{\lambda_{1}}\right) \frac{\underline{v}^{2}+\bar{v}^{2}}{2}-\bar{c} x+q v^{1}+(1-q) \frac{\lambda_{2}}{\lambda_{1}} v^{2} \\
& p_{\lambda}^{3}\left(v^{1}, v^{2}\right)=\frac{q}{2}\left(\frac{\lambda_{2}-\lambda_{1}}{\lambda_{2}}\right) \bar{v}^{1}+\frac{(1-q)}{2}\left(\frac{\lambda_{1}-\lambda_{2}}{\lambda_{1}}\right) \bar{v}^{2}-\bar{c} x+\frac{q}{2} \frac{\lambda_{1}+\lambda_{2}}{\lambda_{2}} v^{1}+\frac{1-q}{2} \frac{\lambda_{1}+\lambda_{2}}{\lambda_{1}} v^{2} .
\end{aligned}
$$

Case B is handled symmetrically, and the calculations are carried out in the appendix. By construction, our price function is a fixed point of the market-clearing equation (2). It is reassuring to note that the price function is continuous across the boundaries.

Now, recall that we had originally assumed that $0 \leq \frac{v^{j}-p}{\bar{c}} \leq 1$ and $0 \leq \frac{E\left[v^{j} \mid p\right]-p}{\bar{c}} \leq 1$ must hold for all $\left(v^{1}, v^{2}\right)$ and $p\left(v^{1}, v^{2}\right)$. We can ensure that these restrictions hold by making restrictions on exogenous parameters. For now, I will provide sufficient conditions that entail fairly restrictive assumptions on exogenous parameters. We can relax these assumptions later. First, note that $v^{j} \geq p\left(v^{i}, v^{j}\right)$ for all $v^{i}, v^{j}$ if $\underline{v}^{j} \geq p\left(\bar{v}^{i}, \bar{v}^{j}\right)$, which holds if

$$
\begin{aligned}
& \bar{c} x \geq q\left(\bar{v}^{1}-\underline{v}^{1}\right)+(1-q)\left(\bar{v}^{2}-\underline{v}^{1}\right) \\
& \bar{c} x \geq q\left(\bar{v}^{1}-\underline{v}^{2}\right)+(1-q)\left(\bar{v}^{2}-\underline{v}^{2}\right)
\end{aligned}
$$

Next, note that $E\left[v^{j} \mid p\right] \geq \underline{v}^{j}$, so that if the previous conditions are satisfied, then $E\left[v^{j} \mid p\right] \geq p\left(v^{i}, v^{j}\right)$ must hold for all $\left(v^{i}, v^{j}\right)$. Next, note that $v^{j} \leq \bar{c}+p\left(v^{i}, v^{j}\right)$ holds for all $\left(v^{i}, v^{j}\right)$ if $\bar{v}^{j} \leq \bar{c}+p\left(\underline{v}^{i}, \underline{v}^{j}\right)$, or

$$
\begin{aligned}
& \bar{c}(1-x) \geq q\left(\bar{v}^{1}-\underline{v}^{1}\right)+(1-q)\left(\bar{v}^{1}-\underline{v}^{2}\right) \\
& \bar{c}(1-x) \geq q\left(\bar{v}^{2}-\underline{v}^{1}\right)+(1-q)\left(\bar{v}^{2}-\underline{v}^{2}\right)
\end{aligned}
$$

Since $E\left[v^{j} \mid p\right] \leq \bar{v}^{j}$, if these conditions are satisfied, then $E\left[v^{j} \mid p\right] \leq \bar{c}+p\left(v^{i}, v^{j}\right)$ must hold for all $\left(v^{i}, v^{j}\right)$. All of these conditions can be ensured if $\bar{c}$ is sufficiently large. However, 
prices are everywhere positive only if $q \underline{v}^{1}+(1-q) \underline{v}^{2} \geq \bar{c} x$ holds. This provides an upper bound and a set of lower bounds on $\bar{c}$. For the special case in which $\underline{v}^{j}=\underline{v}$ and $\bar{v}^{j}=\bar{v}$, these restrictions become

$$
\frac{\underline{v}}{x} \geq \bar{c} \geq \frac{\bar{v}-\underline{v}}{x}
$$

if $x \leq \frac{1}{2}$ and

$$
\frac{\underline{v}}{x} \geq \bar{c} \geq \frac{\bar{v}-\underline{v}}{1-x}
$$

if $x \geq \frac{1}{2}$. The following theorem summarizes these results.

Theorem 1 Given $\lambda_{1}, \lambda_{2}>0$, suppose (4) and (5) are satisfied. There exists an REE characterized by a piecewise-linear price function

$$
p_{\lambda}\left(v^{1}, v^{2}\right)=1_{\left\{(x, v) \in R_{\lambda}^{1}\right\}} p_{\lambda}^{1}\left(v^{1}, v^{2}\right)+1_{\left\{(x, v) \in R_{\lambda}^{2}\right\}} p_{\lambda}^{2}\left(v^{1}, v^{2}\right)+1_{\left\{(x, v) \in R_{\lambda}^{3}\right\}} p_{\lambda}^{3}\left(v^{1}, v^{2}\right)
$$

When $\frac{q}{1-q} \frac{\lambda_{1}}{\lambda_{2}} \geq \frac{\bar{v}^{2}-\underline{v}^{2}}{\bar{v}^{1}-\underline{v}^{1}}$, the price function is given by (3), and when $\frac{q}{1-q} \frac{\lambda_{1}}{\lambda_{2}} \leq \frac{\bar{v}^{2}-\underline{v}^{2}}{\bar{v}^{1}-\underline{v}^{1}}$, the price function is given by (6). Additionally, $p_{\lambda}\left(v^{1}, v^{2}\right)$ is continuous in $\lambda_{1}, \lambda_{2}, v^{1}$, and $v^{2}$ for $\lambda_{1}, \lambda_{2}>0$. When $q \underline{v}^{1}+(1-q) \underline{v}^{2} \geq \bar{c} x$, prices are everywhere positive.

\section{Full Equilibrium}

We now turn to endogenizing information acquisition. Recall that, prior to observing the production cost $\left(c_{i}\right)$ or the price $(p)$, each producer, at cost $k_{i}$, can learn the value of their final good $v^{j}$. Given $\lambda_{1}$ and $\lambda_{2}$, gross of information-acquisition costs, an informed good-j 
producer receives expected payoff

$$
\begin{aligned}
\Pi_{I}^{j}\left(\lambda_{1}, \lambda_{2}\right) & =E_{v^{2}, v^{1}, c_{i}}\left[\pi_{i}^{j}\left(v^{1}, v^{2}, p\right) \mid p_{\lambda}(\cdot, \cdot)=p_{\lambda}\left(v^{1}, v^{2}\right), c_{i}, \varphi_{i}=v^{j}\right] \\
& =\int_{v^{2}}\left[\int_{v^{1}}\left[\begin{array}{c}
\int_{c_{i}}\left(v^{j}-p_{\lambda}\left(v^{1}, v^{2}\right)-c_{i}\right) \\
\cdot 1_{\left\{c_{i}<v^{j}-p_{\lambda}\left(v^{1}, v^{2}\right)\right\}} d F_{c}\left(c_{i}\right)
\end{array}\right] d F_{v^{1}}\left(v^{1}\right)\right] d F_{v 2}\left(v^{2}\right) \\
& =\frac{1}{\bar{v}^{2}-\underline{v}^{2}} \frac{1}{\bar{v}^{1}-\underline{v}^{1}} \frac{1}{2 \bar{c}} \int_{v^{2}}\left[\int_{v^{1}}\left(v^{j}-p_{\lambda}\left(v^{1}, v^{2}\right)\right)^{2} d v^{1}\right] d v^{2}
\end{aligned}
$$

and an uninformed good-j producer receives expected payoff

$$
\begin{aligned}
& \Pi_{U}^{j}\left(\lambda_{1}, \lambda_{2}\right)=E_{v^{2}, v^{1}, c_{i}}\left[\pi_{i}^{j}\left(v^{1}, v^{2}, p\right) \mid p_{\lambda}(\cdot, \cdot)=p_{\lambda}\left(v^{1}, v^{2}\right), c_{i}, \varphi_{i}=\emptyset\right] \\
& =\int_{v^{2}}\left[\int_{v^{1}}\left[\begin{array}{c}
\int_{c_{i}}\left(v^{j}-p_{\lambda}\left(v^{1}, v^{2}\right)-c_{i}\right) \\
\cdot 1_{\left\{c_{i}<E\left[v^{j} \mid p\right]-p_{\lambda}\left(v^{1}, v^{2}\right)\right\}} d F_{c}\left(c_{i}\right)
\end{array}\right] d F_{v^{1}}\left(v^{1}\right)\right] d F_{v^{2}}\left(v^{2}\right) \\
& =\frac{1}{\bar{v}^{2}-\underline{v}^{2}} \frac{1}{\bar{v}^{1}-\underline{v}^{1}} \frac{1}{2 \bar{c}} \int_{v^{2}}\left[\int_{v^{1}}\left(\begin{array}{c}
2 v^{j} E\left[v^{j} \mid p\right]-\left(E\left[v^{j} \mid p\right]\right)^{2} \\
-2 v^{j} p_{\lambda}\left(v^{1}, v^{2}\right) \\
+\left(p_{\lambda}\left(v^{1}, v^{2}\right)\right)^{2}
\end{array}\right) d v^{1}\right] d v^{2}
\end{aligned}
$$

Depending on whether or not $\frac{q}{1-q} \frac{\lambda_{1}}{\lambda_{2}} \geq \frac{\bar{v}^{2}-\underline{v}^{2}}{\bar{v}^{1}-\underline{v}^{1}}$, the expressions for $E\left[v^{j} \mid p\right]$ and $p_{\lambda}\left(v^{1}, v^{2}\right)$ are determined based on the pricing function from case A or case B. A good-j producer will become informed if the expected benefits of doing so exceed the private costs, or

$$
\Delta^{j}\left(\lambda_{1}, \lambda_{2}\right)=\Pi_{I}^{j}\left(\lambda_{1}, \lambda_{2}\right)-\Pi_{U}^{j}\left(\lambda_{1}, \lambda_{2}\right) \geq k_{i}
$$

In words, in period one, each producer will consider all possible states of the world $\left(v^{1}, v^{2}, c_{i}\right)$ that may arise, the price of the widget that arises in each state, her expectations of the relevant $v^{j}$ (if uninformed) given that particular price, and the cost of the decision-making error that arises from producing (or not) a final good without using all the information. The expected cost of such decision-making errors is then compared to the private cost of becoming informed. 
A full equilibrium is defined as follows.

Definition 2 A full equilibrium is a pair of fractions $\lambda_{1}^{*}, \lambda_{2}^{*}$, a price function $p_{\lambda}(\cdot, \cdot)$, and a production allocation $\left\{q_{i}^{j *}\right\}_{i \in[0,1]}$ such that

1. A fraction $\lambda_{j}^{*}$ of good-j producers optimally choose to become informed for $j=1,2$.

2. $q_{i}^{j *} \in \operatorname{argmax}_{q_{i}^{j} \in\{0,1\}} E_{v^{1}, v^{2}}\left[\pi_{i}^{j}\left(v^{1}, v^{2}, p\right) \mid p_{\lambda}(\cdot, \cdot)=p, s_{i}\right]$ for all $i$, for $j=1,2$.

3. (2) holds for all $v^{1}, v^{2}$.

The remaining task is to compute the difference in expected utility $\Delta^{j}\left(\lambda_{1}, \lambda_{2}\right)$ for $j=1,2$ for both case A and case B.

$$
\Delta^{j}\left(\lambda_{1}, \lambda_{2}\right)=\frac{1}{\bar{v}^{2}-\underline{v}^{2}} \frac{1}{\bar{v}^{1}-\underline{v}^{1}} \frac{1}{2 \bar{c}} \int_{v^{2}}\left[\int_{v^{1}}\left(v^{j}-E\left[v^{j} \mid p\right]\right)^{2} d v^{1}\right] d v^{2}=\frac{E_{v^{1} v^{2}}\left[\sigma_{v^{j} \mid p}^{2}\right]}{2 \bar{c}}
$$

The actual computations are somewhat laborious, and they are carried out in the appendix. The results are given by

$$
\begin{aligned}
& \Delta^{1}\left(\lambda_{1}, \lambda_{2}\right)=\left\{\begin{array}{ccc}
\left(\frac{1}{K\left(\lambda_{1}, \lambda_{2}\right)}\right)^{2} \frac{\sigma_{v 1}^{2}}{2 \bar{c}}\left(1-\frac{1}{2} \frac{1}{K\left(\lambda_{1}, \lambda_{2}\right)}\right) & \text { if } & K\left(\lambda_{1}, \lambda_{2}\right) \geq 1 \\
\frac{\sigma_{v 1}^{2}}{2 \bar{c}}\left(1-\frac{1}{2} K\left(\lambda_{1}, \lambda_{2}\right)\right) & \text { if } & K\left(\lambda_{1}, \lambda_{2}\right) \leq 1
\end{array}\right. \\
& \Delta^{2}\left(\lambda_{1}, \lambda_{2}\right)=\left\{\begin{array}{cll}
\frac{\sigma_{v 2}^{2}}{2 \bar{c}}\left(1-\frac{1}{2} \frac{1}{K\left(\lambda_{1}, \lambda_{2}\right)}\right) & \text { if } \quad K\left(\lambda_{1}, \lambda_{2}\right) \geq 1 \\
\left(K\left(\lambda_{1}, \lambda_{2}\right)\right)^{2} \frac{\sigma_{v 2}^{2}}{2 \bar{c}}\left(1-\frac{1}{2}\left(K\left(\lambda_{1}, \lambda_{2}\right)\right)\right) & \text { if } & K\left(\lambda_{1}, \lambda_{2}\right) \leq 1
\end{array}\right.
\end{aligned}
$$

where $K\left(\lambda_{1}, \lambda_{2}\right)=\frac{q}{1-q} \frac{\lambda_{1}}{\lambda_{2}} \frac{\sigma_{v 1}}{\sigma_{v^{2}}}$. Note that when $K\left(\lambda_{1}, \lambda_{2}\right) \geq 1$, we are in case A, and prices are more informative for group 1 . When $K\left(\lambda_{1}, \lambda_{2}\right) \leq 1$, we are in case $\mathrm{B}$, and prices are more informative for group 2. When $K\left(\lambda_{1}, \lambda_{2}\right)=1$, we are in the knife's edge case where prices are equally informative for both groups. 


\subsection{Information Acquisition}

Since profits are separable in the costs of becoming informed, any full equilibrium with interior values of $\lambda_{1}, \lambda_{2}$ must involve cutoff values $k_{1}^{*}\left(\lambda_{2}\right)$ and $k_{2}^{*}\left(\lambda_{1}\right)$ such that a good-1 producer chooses to become informed if and only if $k_{i} \leq k_{1}^{*}\left(\lambda_{2}\right)$ and a good-2 producer chooses to become informed if and only if $k_{i} \leq k_{2}^{*}\left(\lambda_{1}\right)$. Given the assumption that $k_{i} \sim$ $U[0, \bar{k}],{ }^{2}$ the fraction of parties that is informed is then $\lambda_{1}^{*}\left(\lambda_{2}\right)=\frac{k_{1}^{*}\left(\lambda_{2}\right)}{k}$ and $\lambda_{2}^{*}\left(\lambda_{1}\right)=\frac{k_{2}^{*}\left(\lambda_{1}\right)}{k}$. The values $k_{1}^{*}\left(\lambda_{2}\right)$ and $k_{2}^{*}\left(\lambda_{1}\right)$ solve, respectively,

$$
\begin{aligned}
\Delta^{1}\left(\lambda_{1}^{*}\left(\lambda_{2}\right), \lambda_{2}\right) & =k_{1}^{*}\left(\lambda_{2}\right)=\lambda_{1}^{*}\left(\lambda_{2}\right) \bar{k} \\
\Delta^{2}\left(\lambda_{1}, \lambda_{2}^{*}\left(\lambda_{1}\right)\right) & =k_{2}^{*}\left(\lambda_{1}\right)=\lambda_{2}^{*}\left(\lambda_{1}\right) \bar{k} .
\end{aligned}
$$

It is helpful to fix $\lambda_{j}$ and plot $\Delta^{i}\left(\lambda_{i}, \lambda_{j}\right)-\bar{k} \lambda_{i}$, which is done in the following graph.

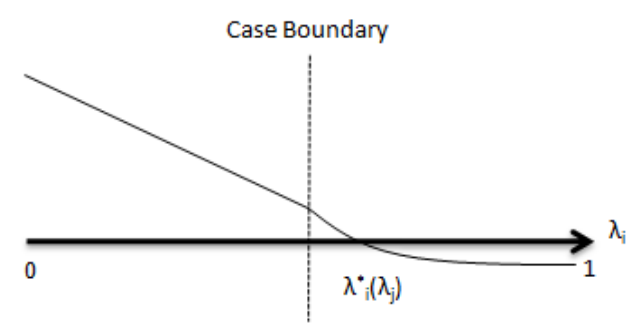

We see that for a fixed $\lambda_{j}, \Delta^{i}\left(\lambda_{i}, \lambda_{j}\right)-\bar{k} \lambda_{i}$ is strictly decreasing in $\lambda_{i}$. It is linear to the left of the case boundary for which $K\left(\lambda_{1}, \lambda_{2}\right)=1$ and nonlinear to the right. An increase in $\lambda_{j}$ will shift this entire curve upward. An interior equilibrium will then be a fixed point of the equations

$$
\begin{aligned}
\Delta^{1}\left(\lambda_{1}^{*}, \lambda_{2}^{*}\right) & =\lambda_{1}^{*} \bar{k} \\
\Delta^{2}\left(\lambda_{1}^{*}, \lambda_{2}^{*}\right) & =\lambda_{2}^{*} \bar{k}
\end{aligned}
$$

\footnotetext{
${ }^{2}$ Heterogeneous information costs simplify the analysis but are not necessary for the qualitative results, since the returns to information acquisition are endogenous.
} 
Define $\lambda_{i}^{*}\left(\lambda_{j}\right)$ to be the group best-response of good- $i$ producers when a fraction $\lambda_{j}$ of good- $j$ producers is informed. The following graph plots the group best-response functions. The intersection of the two group best-response functions gives us $\lambda_{1}^{*}, \lambda_{2}^{*}$, which in turn gives us $k_{1}^{*}$ and $k_{2}^{*}$. Good-1 producers will become informed if and only if $k_{i} \leq k_{1}^{*}$ and good-2 producers will become informed if and only if $k_{i} \leq k_{2}^{*}$.

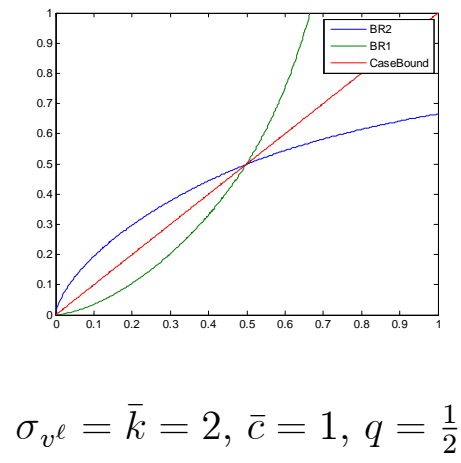

From this plot, we see several facts about this model, which turn out to be quite general. First, the group best-response functions appear to intersect at the origin. This turns out not to be the case, because neither group best-response function is well-defined at the origin, since the benefits to becoming informed depend on the ratio $\frac{\lambda_{i}}{\lambda_{j}}$. Thus, there is no equilibrium in which $\lambda_{1}^{*}=\lambda_{2}^{*}=0$. Secondly, the good- $j$ group best-response function is increasing in $\lambda_{i}$. This is consistent with the idea that cross-group information acquisition exhibits strategic complementarities. Intuitively, as more good-1 producers become informed, prices become more informative for good-1 producers and hence less informative for good-2 producers, which in turn increases $k_{2}^{*}$ and hence $\lambda_{2}^{*}$. Third, for $\lambda_{1}>0$ very small, $\lambda_{2}^{*}\left(\lambda_{1}\right)>\lambda_{1}^{*-1}\left(\lambda_{1}\right)$. That is, the group 2 best-response function lies above the group 1 best-response function for $\lambda_{1}$ arbitrarily small. Fourth, the good- $j$ group best-response function is globally concave. As more good $-i$ producers become informed, the benefit for a good- $j$ producer increases, but at a decreasing rate. The informativeness of prices for good- $i$ depends on $\frac{\lambda_{i}}{\lambda_{j}}$. This is decreasing in $\lambda_{j}$, but at a decreasing rate. The following lemmas establish that these 
characteristics are in fact true.

Lemma $1 \lim _{\lambda_{j} \downarrow 0} \lambda_{i}^{*}\left(\lambda_{j}\right)=0$.

Lemma $2 \lambda_{i}^{*}\left(\lambda_{j}\right)$ is increasing in $\lambda_{j}$.

Lemma $3 \lim _{\lambda_{j} \downarrow 0} \frac{\lambda_{i}^{*}\left(\lambda_{j}\right)}{\lambda_{j}}=+\infty$

Lemma $4 \lambda_{i}^{*}\left(\lambda_{j}\right)$ is globally concave in $\lambda_{j}$.

We know that for arbitrarily small $\lambda_{1}, \lambda_{2}^{*}\left(\lambda_{1}\right)>\lambda_{1}^{*-1}\left(\lambda_{1}\right)$. There are two cases $\lambda_{2}^{*}(1) \geq$ $\lambda_{1}^{*-1}(1)$ or $\lambda_{2}^{*}(1)<\lambda_{1}^{*-1}(1)$. In the former case, there is an equilibrium at $\lambda_{1}^{*}=\lambda_{2}^{*}=1$. In the latter case, there must be some $0<\lambda_{1}^{*}<1$ such that $\lambda_{2}^{*}\left(\lambda_{1}^{*}\right)=\lambda_{1}^{*-1}\left(\lambda_{1}^{*}\right)$. Since $\lambda_{2}^{*}\left(\lambda_{1}\right)-\lambda_{1}^{*-1}\left(\lambda_{1}\right)$ is concave, there can be at most one such point. Putting these facts together gives us the following proposition.

Theorem 2 There exists a unique full equilibrium in which $\lambda_{1}^{*}, \lambda_{2}^{*}>0$. Consistent with the Grossman-Stiglitz paradox, there does not exist an equilibrium in which $\lambda_{1}^{*}=\lambda_{2}^{*}=0$.

We next establish some properties of the equilibrium.

Proposition $1 \lambda_{i}^{*}$ and $\lambda_{j}^{*}$ are increasing in $\sigma_{v^{i}}, \lambda_{i}^{*}$ is decreasing in $\bar{k}$. Finally, $\lambda_{1}^{*}$ is decreasing in $q$, and $\lambda_{2}^{*}$ is increasing in $q$.

Proof. $\Delta^{i}\left(\lambda_{i}, \lambda_{j}\right)-\bar{k} \lambda_{i}$ is increasing in $\sigma_{v^{i}}$ and decreasing in $\bar{k}$. For a fixed $\lambda_{j}$, this implies that $\lambda_{i}$ is increasing in $\sigma_{v^{i}}$ and decreasing in $\bar{k}$. Cross-group strategic complementarities implies that both $\lambda_{i}^{*}$ and $\lambda_{j}^{*}$ increase in $\sigma_{v^{i}}$ and decrease in $\bar{k}$. Fixing $\lambda_{1}$ and $\lambda_{2}, \Delta^{1}\left(\lambda_{1}, \lambda_{2}\right)$ is decreasing in $q$ and $\Delta^{2}\left(\lambda_{1}, \lambda_{2}\right)$ is increasing in $q$. This implies that $\lambda_{1}^{*}\left(\lambda_{2}\right)$ is decreasing in $q$ and $\lambda_{2}^{*}\left(\lambda_{1}\right)$ is increasing in $q$, which in turn implies that $\lambda_{1}^{*}$ is decreasing in $q$ and $\lambda_{2}^{*}$ is increasing in $q$. 


\section{$5 \quad$ GS Conjectures}

Grossman and Stiglitz (1980) begin their paper by making seven conjectures, saying that they may or may not be true in general, and then develop their CARA-Normal model in which all seven are indeed true. We now discuss these seven conjectures in the context of our model.

Conjecture 1 (GS 1) The more players who are informed, the more informative is the price mechanism.

GS use the Blackwell criterion to order information systems. That criterion is not applicable here, as it does not order uniform distributions with different supports. One simple way to proceed is to define the informativeness of the price mechanism for $v^{j}$ as the expected reduction in the variance of $v^{j}$ that results from observing $p$. Define $I^{j}(\lambda)=$ $E_{v^{1}, v^{2}}\left[\sigma_{v^{j}}^{2}-\sigma_{v^{j} \mid p}^{2}\right]$, where $\lambda=\left(\lambda_{1}, \lambda_{2}\right)$. We then have that

$$
\begin{aligned}
& I^{1}(\lambda)=\left\{\begin{array}{ccc}
\sigma_{v^{1}}^{2}\left[1-\left(\frac{1}{K\left(\lambda_{1}, \lambda_{2}\right)}\right)^{2}+\frac{1}{2}\left(\frac{1}{K\left(\lambda_{1}, \lambda_{2}\right)}\right)^{3}\right] & \text { if } & K\left(\lambda_{1}, \lambda_{2}\right) \geq 1 \\
\sigma_{v^{1}}^{2} \frac{1}{2} K\left(\lambda_{1}, \lambda_{2}\right) & \text { if } & K\left(\lambda_{1}, \lambda_{2}\right) \leq 1
\end{array}\right. \\
& I^{2}(\lambda)=\left\{\begin{array}{ccc}
\sigma_{v^{2}}^{2} \frac{1}{2} \frac{1}{K\left(\lambda_{1}, \lambda_{2}\right)} & \text { if } & K\left(\lambda_{1}, \lambda_{2}\right) \geq 1 \\
\sigma_{v^{2}}^{2}\left[1-\left(K\left(\lambda_{1}, \lambda_{2}\right)\right)^{2}+\frac{1}{2}\left(K\left(\lambda_{1}, \lambda_{2}\right)\right)^{3}\right] & \text { if } & K\left(\lambda_{1}, \lambda_{2}\right) \leq 1
\end{array}\right.
\end{aligned}
$$

Evaluating this claim in the context of our model highlights the need to consider $(a)$ who is becoming more informed and $(b)$ what the price mechanism is becoming more informative about. If more good-1 producers are informed, then prices will become more informative for good-1 producers, all else equal, and less informative for good-2 producers. Further, note that $I^{j}(\lambda)$ depends on $\left(\lambda_{1}, \lambda_{2}\right)$ only inasmuch as it depends on $K\left(\lambda_{1}, \lambda_{2}\right)=\frac{q}{1-q} \frac{\lambda_{1}}{\lambda_{2}} \frac{\sigma_{v 1}}{\sigma_{v^{2}}}$, which depends only on the ratio of $\lambda_{1}$ to $\lambda_{2}$. For a given $\left(\lambda_{1}, \lambda_{2}\right)$ pair, if both increase proportionally by the same amount (i.e. $\left(\lambda_{1}, \lambda_{2}\right) \mapsto\left((1+\alpha) \lambda_{1},(1+\alpha) \lambda_{2}\right)$ for $\left.0<\alpha \leq \min _{j}\left\{\frac{1}{\lambda_{j}}-1\right\}\right)$, then the informativeness of the price system does not change for either group. That is, 
$I^{j}((1+\alpha) \lambda)=I^{j}(\lambda)$.

Conjecture 2 (GS 2) The more players who are informed, the lower the ratio of the expected utility of the informed to the uninformed.

For GS, the ratio of expected utility of the informed to the uninformed plays an integral role in computing the fraction of parties who are informed, and this conjecture provides the monotonicity required to ensure the existence and uniqueness of a solution. In our paper, the difference (rather than the ratio) in the expected utilities of the informed and the uninformed plays the analogous role. Focusing on good-1 producers, this difference, $\Delta^{1}\left(\lambda_{1}, \lambda_{2}\right)$ is decreasing in $\lambda_{1}$, which is consistent with their conjecture. Within-group information acquisition is a strategic substitute. $\Delta^{1}\left(\lambda_{1}, \lambda_{2}\right)$ is increasing in $\lambda_{2}$, however, which is inconsistent with their conjecture. Cross-group information acquisition is a strategic complement in our model. A literature has developed around establishing the existence of strategic complementarities in information acquisition ${ }^{3}$. Our model does so in what we feel is a very natural way. Strategic complementarities often yield multiple equilibria, but not in our particular model, due to the discontinuity in the group best-response functions at the origin.

Conjecture 3 (GS 3) The higher the cost of information, the smaller is the number of players who are informed in equilibrium.

Our model features heterogeneous costs of acquiring information, so we need to define what it means for the cost of information to increase. If we define an increase in the cost of information acquisition as a first-order stochastic dominant shift in the distribution of information costs, then for our model, this corresponds to increasing $\bar{k}$. We know that $\Delta^{j}\left(\lambda_{i}, \lambda_{j}\right)-\bar{k} \lambda_{j}$ is decreasing in $\bar{k}$, so it is clearly the case that $\lambda_{j}^{*}$ is decreasing in $\bar{k}$. Somewhat interestingly, suppose good-1 producers have $k_{i} \sim U\left[0, \bar{k}^{1}\right]$ and good-2 producers have $k_{i} \sim U\left[0, \bar{k}^{2}\right]$. As we just argued, it will clearly be the case that $\lambda_{j}^{*}$ is decreasing in $\bar{k}^{j}$.

\footnotetext{
${ }^{3}$ Barlevy, Veronesi (2000, 2008), Chamley (2007, 2008)
} 
However, it turns out that $\lambda_{j}^{*}$ is also decreasing in $\bar{k}^{i}$. This is true, because $\lambda_{i}^{*}$ decreases in $\bar{k}^{i}$. Since information acquisition exhibits cross-group strategic complementarities, a decrease in $\lambda_{i}^{*}$ will then lead to a decrease in $\lambda_{j}^{*}$.

Conjecture 4 (GS 4) If the quality of information of the informed players increases then the price system becomes more informative, but the equilibrium number of informed traders may increase or decrease.

In our model, if a producer pays $k_{i}$, she becomes perfectly informed with probability one. We have analyzed an extension in which, instead, she becomes informed with probability $r$ and remains uninformed with probability $1-r$. An increase in the quality of information of the informed can be thought of as an increase in $r$. In this extension, a good-j producer becomes informed if and only if

$$
\Delta^{j}\left(\lambda_{i}, \lambda_{j}\right) \geq \frac{k_{i}}{r}
$$

The condition for an (interior) equilibrium is then that $\left(\lambda_{i}^{*}, \lambda_{j}^{*}\right)$ satisfy

$$
\begin{aligned}
\Delta^{1}\left(\lambda_{1}^{*}, \lambda_{2}^{*}\right) & =\lambda_{1}^{*} \frac{\bar{k}}{r} \\
\Delta^{2}\left(\lambda_{1}^{*}, \lambda_{2}^{*}\right) & =\lambda_{2}^{*} \frac{\bar{k}}{r}
\end{aligned}
$$

The quality of information plays the opposite role as $\bar{k}$, the upper bound on the cost of acquiring information. In particular, we know that as $r$ increases, a larger fraction of parties will become informed in equilibrium. In this model, this yields ambiguous effects about the overall informativeness of prices, so in some sense, this conjecture is reversed.

Conjecture 5 (GS 5) When there is more noise, more players become informed in equilibrium.

There is no noise in our model, but it is true that if $\sigma_{v^{j}}$ increases, both $\lambda_{i}^{*}$ and $\lambda_{j}^{*}$ will increase. An increase in the uncertainty in the model increases the fraction of producers who become informed. 
Conjecture 6 (GS 6) "In the limit, when there is no noise, prices convey all information, and there is no incentive to purchase information. Hence, the only possible equilibrium is one with no information. But if everyone is uninformed, it clearly pays some individual to become informed. Thus, there does not exist a competitive equilibrium."

It has been shown elsewhere in the literature ${ }^{4}$ that if market participants are informationally large, in the sense that they recognize that their decision of whether or not to acquire information affects the overall informativeness of the price system, this conjecture is no longer true. In our model, producers are in fact informationally small, and this classic GS non-existence result manifests itself as a discontinuity in the group best-response functions at the origin.

Conjecture 7 (GS 7) Markets are thinner when $\lambda^{*}$ is close to zero or one.

Market thickness in Grossman-Stiglitz is defined as the per-capita quantity of trades occurring on the basis of differences in information. Difficulties arise in GS, because as $\lambda \rightarrow 0$, the trade of informed parties could potentially explode at a fast enough rate to prevent per-capita trades from tending to zero. In our model, the fact that no producer has any use for more than a single widget prevents this from occurring.

\section{Conclusion}

This paper constructs a rational-expectations model of information acquisition and price formation in an intermediate-good market in which prices and net supply are always positive and no producer trades on noise. The intermediate good has two potential uses with independent values.

We emphasize several differences from the classic Grossman-Stiglitz model. For example, the price mechanism is more informative at high and low prices and potentially uninformative at middle prices. Also, an informed trade by a producer of one final good amounts

\footnotetext{
${ }^{4}$ Krebs (2007), Muendler (2007)
} 
to a noise trade from the perspective of a producer of another final good, so (a) as the price mechanism becomes more informative for producers of one final good, it becomes less informative for producers of others, who therefore have a stronger incentive to acquire information, so information acquisition has the strategic-complements property between groups,

and (b) having more producers (in multiple groups) become informed need not increase the informativeness of the price mechanism.

The idea that there are conflicting forces determining the information content of prices may apply in financial markets where different traders trade for different reasons (e.g., liquidity, hedging, or value). From one trader's perspective, if other traders are trading for reasons she is not concerned about, then the fact that they are more informed about their reasons for trading may merely increase the noise she faces.

In Gibbons et. al. (2009), we simplify this model of price formation and then embed it in a richer setting, where the single player in this model is replaced by a dyad of upstream and downstream parties. In a given dyad, the parties may or may not be integrated, and they may or may not acquire information before participating in the intermediate-good market (where upstream parties may sell the intermediate good and downstream may buy). This model allows us to combine the single-dyad analysis of the integration decision that is typical of the transaction-cost and property-rights literatures with the present paper's analysis of the price mechanism in intermediate-good markets.

\section{References}

Admati, A. R. (1985). A noisy rational expectations equilibrium for Multi-Asset securities markets. Econometrica 53(3), 629-657.

Ausubel, L. (1990). Partially-Revealing rational expectations equilibrium in a competitive economy. Journal of Economic Theory 50(1), 93-126. 
Barlevy, G. and P. Veronesi (2000). Information acquisition in financial markets. The Review of Economic Studies 67(1), 79-90.

Barlevy, G. and P. Veronesi (2008). Information acquisition in financial markets: A correction. Review of Economic Studies, forthcoming.

Black, F. (1986). Noise. The Journal of Finance 41(3), 529-543.

Chamley, C. (2007). Complementarities in information acquisition with Short-Term trades. Theoretical Economics 2(4), 441-467.

Chamley, C. (2008). On "Acquisition of information in financial markets". The Review of Economic Studies 75(4), 1081-1084.

Ganguli, J. V. and L. Yang (2009). Complementarities, multiplicity, and supply information. Journal of the European Economic Association 7(1), 90-115.

Gibbons, R. S., R. T. Holden, and M. L. Powell (2009). Integration and information: Markets and hierarchies revisited. Massachusetts Institute of Technology Working Paper.

Grossman, S. J. (1976). On the efficiency of competitive stock markets where trades have diverse information. Journal of Finance, 573-585.

Grossman, S. J. (1977). The existence of futures markets, noisy rational expectations and informational externalities. The Review of Economic Studies, 431-449.

Grossman, S. J. and O. D. Hart (1986). The costs and benefits of ownership: A theory of vertical and lateral integration. The Journal of Political Economy 94(4), 691.

Grossman, S. J. and J. E. Stiglitz (1976). Information and competitive price systems. The American Economic Review 66(2), 246-253.

Grossman, S. J. and J. E. Stiglitz (1980). On the impossibility of informationally efficient markets. The American Economic Review 70(3), 393-408. 
Hayek, F. A. (1945). The use of knowledge in society. American Economic Review 35(4), 519-530.

Hellwig, M. (1980). On the aggregation of information in competitive markets. Journal of Economic Theory 22(3), 477-498.

Klein, B., R. G. Crawford, and A. A. Alchian (1978). Vertical integration, appropriable rents, and the competitive contracting process. The Journal of Law and Economics 21(2), 297.

Krebs, T. (2007). Rational expectations equilibrium and the strategic choice of costly information. Journal of Mathematical Economics 43(5), 532-548.

Muendler, M. (2007). The possibility of informationally efficient markets. Journal of Economic Theory 133(1), 467-483.

Veldkamp, L. L. (2006). Information markets and the comovement of asset prices. Review of Economic Studies 73(3), 823.

Verrecchia, R. E. (1982). Information acquisition in a noisy rational expectations economy. Econometrica: Journal of the Econometric Society, 1415-1430.

Wang, J. (1993). A model of intertemporal asset prices under asymmetric information. The Review of Economic Studies, 249-282.

Williamson, O. E. (1971). The vertical integration of production: Market failure considerations. The American Economic Review, 112-123. 


\section{Appendix}

\section{Case B Price Function}

There are three regions:

$$
\begin{aligned}
& R_{\lambda}^{1}=\left\{\left(v^{1}, v^{2}\right): \underline{p} \leq p_{\lambda}\left(v^{1}, v^{2}\right) \leq p_{\lambda}\left(\bar{v}^{1}, \underline{v}^{2}\right)\right\} \\
& R_{\lambda}^{2}=\left\{\left(v^{1}, v^{2}\right): p_{\lambda}\left(\bar{v}^{1}, \underline{v}^{2}\right) \leq p_{\lambda}\left(v^{1}, v^{2}\right) \leq p_{\lambda}\left(\underline{v}^{1}, \bar{v}^{2}\right)\right\} \\
& R_{\lambda}^{3}=\left\{\left(v^{1}, v^{2}\right): p_{\lambda}\left(\underline{v}^{1}, \bar{v}^{2}\right) \leq p_{\lambda}\left(v^{1}, v^{2}\right) \leq \bar{p}\right\}
\end{aligned}
$$

We conjecture that there is a piecewise-linear price function

$$
\begin{aligned}
p_{\lambda}\left(v^{1}, v^{2}\right)= & 1_{\left\{(x, v) \in R_{\lambda}^{1}\right\}}\left[\beta_{0}^{1}+\beta_{1}^{1} v^{1}+\beta_{2}^{1} v^{2}\right]+1_{\left\{(x, v) \in R_{\lambda}^{2}\right\}}\left[\beta_{0}^{2}+\beta_{1}^{2} v^{1}+\beta_{2}^{2} v^{2}\right] \\
& +1_{\left\{(x, v) \in R_{\lambda}^{3}\right\}}\left[\beta_{0}^{3}+\beta_{1}^{3} v^{1}+\beta_{2}^{3} v^{2}\right] \\
= & 1_{\left\{(x, v) \in R_{\lambda}^{1}\right\}} p_{\lambda}^{1}\left(v^{1}, v^{2}\right)+1_{\left\{(x, v) \in R_{\lambda}^{2}\right\}} p_{\lambda}^{2}\left(v^{1}, v^{2}\right)+1_{\left\{(x, v) \in R_{\lambda}^{3}\right\}} p_{\lambda}^{3}\left(v^{1}, v^{2}\right),
\end{aligned}
$$

which is a fixed point of the equation

$$
\begin{aligned}
& q\left(1-\lambda_{1}\right) E\left[v^{1} \mid p_{\lambda}(\cdot, \cdot)=p_{\lambda}\left(v^{1}, v^{2}\right)\right] \\
& +(1-q)\left(1-\lambda_{2}\right) E\left[v^{2} \mid p_{\lambda}(\cdot, \cdot)=p_{\lambda}\left(v^{1}, v^{2}\right)\right] \\
= & p+\bar{c} x-q \lambda_{1} v^{1}-(1-q) \lambda_{2} v^{2},
\end{aligned}
$$

and we seek to solve for the parameter vectors $\beta^{1}, \beta^{2}$, and $\beta^{3}$. To solve for $\beta^{1}$, assume $p \leq p_{\lambda}\left(\underline{v}^{1}, \bar{v}^{2}\right)$. Then individuals believe that

$$
\begin{aligned}
& v^{1} \mid p_{\lambda}(\cdot, \cdot)=p \sim U\left[\underline{v}^{1}(p), \bar{v}^{1}(p)\right] \\
& v^{2} \mid p_{\lambda}(\cdot, \cdot)=p \sim U\left[\underline{v}^{2}(p), \bar{v}^{2}(p)\right]
\end{aligned}
$$


where $\underline{v}^{j}(p)$ and $\bar{v}^{j}(p)$ are, respectively, the lowest and highest values of $v^{j}$ consistent with the realized price level. It can be shown that $\underline{v}^{j}(p)=\underline{v}^{j}$ and $\bar{v}^{1}(p)$ solves

$$
p_{\lambda}\left(\bar{v}^{1}(p), \underline{v}^{2}\right)=p
$$

or

$$
\bar{v}^{1}(p)=\frac{1}{\beta_{1}^{1}}\left(p-\beta_{0}^{1}-\beta_{2}^{1} \underline{v}^{2}\right) .
$$

Given a price $p \leq p_{\lambda}\left(\bar{v}^{1}, \underline{v}^{2}\right)$, the conditional expectation of $v^{1}$ is then

$$
E\left[v^{1} \mid p\right]=\frac{\underline{v}^{1}(p)+\bar{v}^{1}(p)}{2}=\frac{\underline{v}^{1}+\frac{1}{\beta_{1}^{1}}\left(p-\beta_{0}^{1}-\beta_{2}^{1} \underline{v}^{2}\right)}{2} .
$$

Similarly, $\bar{v}^{2}(p)$ solves

$$
p_{\lambda}^{2}\left(\underline{v}^{1}, \bar{v}^{2}(p)\right)=p
$$

or

$$
\bar{v}^{2}(p)=\frac{1}{\beta_{2}^{1}}\left(p-\beta_{0}^{1}-\beta_{1}^{1} \underline{v}^{1}\right) .
$$

The conditional expectation of $v^{2}$ is then

$$
E\left[v^{2} \mid p\right]=\frac{\underline{v}^{2}(p)+\bar{v}^{2}(p)}{2}=\frac{\underline{v}^{2}+\left(1 / \beta_{2}^{1}\right)\left(p-\beta_{0}^{1}-\beta_{1}^{1} \underline{v}^{1}\right)}{2}
$$

Market clearing in (1) then requires

$$
\begin{aligned}
& q\left(1-\lambda_{1}\right) \frac{\underline{v}^{1}+\left(1 / \beta_{1}^{1}\right)\left(\left(\beta_{0}^{1}+\beta_{1}^{1} v^{1}+\beta_{2}^{1} v^{2}\right)-\beta_{0}^{1}-\beta_{2}^{1} \underline{v}^{2}\right)}{2} \\
& +(1-q)\left(1-\lambda_{2}\right) \frac{\underline{v}^{2}+\left(1 / \beta_{2}^{1}\right)\left(\left(\beta_{0}^{1}+\beta_{1}^{1} v^{1}+\beta_{2}^{1} v^{2}\right)-\beta_{0}^{1}-\beta_{1}^{1} \underline{v}^{1}\right)}{2} \\
\equiv & \left(\beta_{0}^{1}+\beta_{1}^{1} v^{1}+\beta_{2}^{1} v^{2}\right)+\bar{c} x-q \lambda_{1} v^{1}-(1-q) \lambda_{2} v^{2},
\end{aligned}
$$

where the equivalence relation reminds us that this holds as an identity in $\left(v^{1}, v^{2}\right)$. Thus, 
we must have that

$$
\begin{aligned}
q\left(1+\lambda_{1}\right) & =\beta_{1}^{1}\left(2-(1-q)\left(1-\lambda_{2}\right) \frac{1}{\beta_{2}^{1}}\right) \\
(1-q)\left(1+\lambda_{2}\right) & =\beta_{2}^{1}\left(2-q\left(1-\lambda_{1}\right) \frac{1}{\beta_{1}^{1}}\right) \\
\beta_{0}^{1} & =q\left(1-\lambda_{1}\right) \frac{\underline{v}^{1}-\frac{\beta_{2}^{1}}{\beta_{1}^{1}} \underline{v}^{2}}{2}+(1-q)\left(1-\lambda_{2}\right) \frac{\underline{v}^{2}-\frac{\beta_{1}^{1}}{\beta_{2}^{1}} \underline{v}^{1}}{2}+\bar{c} x
\end{aligned}
$$

or if we rearrange,

$$
\begin{aligned}
& \beta_{0}^{1}=\frac{q}{2}\left(\frac{\lambda_{2}-\lambda_{1}}{\lambda_{2}}\right) \underline{v}^{1}+\frac{(1-q)}{2}\left(\frac{\lambda_{1}-\lambda_{2}}{\lambda_{1}}\right) \underline{v}^{2}-\bar{c} x \\
& \beta_{1}^{1}=\frac{q}{2} \frac{\lambda_{1}+\lambda_{2}}{\lambda_{2}} \\
& \beta_{2}^{1}=\frac{1-q}{2} \frac{\lambda_{1}+\lambda_{2}}{\lambda_{1}}
\end{aligned}
$$

Similar calculations can be carried out for regions 2 and 3 , in which $p_{\lambda}\left(\underline{v}^{1}, \bar{v}^{2}\right)<p \leq$ $p_{\lambda}\left(\bar{v}^{1}, \underline{v}^{2}\right)$ and $p>p_{\lambda}\left(\bar{v}^{1}, \underline{v}^{2}\right)$, respectively, in which case we get

$$
\begin{aligned}
& p_{\lambda}^{1}\left(v^{1}, v^{2}\right)=\frac{q}{2}\left(\frac{\lambda_{2}-\lambda_{1}}{\lambda_{2}}\right) \underline{v}^{1}+\frac{1-q}{2}\left(\frac{\lambda_{1}-\lambda_{2}}{\lambda_{1}}\right) \underline{v}^{2}-\bar{c} x+\frac{q}{2} \frac{\lambda_{1}+\lambda_{2}}{\lambda_{2}} v^{1}+\frac{1-q}{2} \frac{\lambda_{1}+\lambda_{2}}{\lambda_{1}} v^{2} \\
& p_{\lambda}^{2}\left(v^{1}, v^{2}\right)=q\left(\frac{\lambda_{2}-\lambda_{1}}{\lambda_{2}}\right) \frac{\underline{v}^{1}+\bar{v}^{1}}{2}-\bar{c} x+q \frac{\lambda_{1}}{\lambda_{2}} v^{1}+(1-q) v^{2} \\
& p_{\lambda}^{3}\left(v^{1}, v^{2}\right)=\frac{q}{2}\left(\frac{\lambda_{2}-\lambda_{1}}{\lambda_{2}}\right) \bar{v}^{1}+\frac{(1-q)}{2}\left(\frac{\lambda_{1}-\lambda_{2}}{\lambda_{1}}\right) \bar{v}^{2}-\bar{c} x+\frac{q}{2} \frac{\lambda_{1}+\lambda_{2}}{\lambda_{2}} v^{1}+\frac{1-q}{2} \frac{\lambda_{1}+\lambda_{2}}{\lambda_{1}} v^{2}
\end{aligned}
$$

\section{Explicit Computations}

\section{Case A}

For now, let us assume that

$$
\frac{q}{1-q} \frac{\lambda_{1}}{\lambda_{2}} \geq \frac{\bar{v}^{2}-\underline{v}^{2}}{\bar{v}^{1}-\underline{v}^{1}}
$$

so that we are in case A. We can then compute these integrals using the price functions 
we derived in the previous section. First note that

$$
\begin{aligned}
& \mu_{v^{1} p}^{1}=\mu_{v^{1} p}^{2}-\frac{v^{1}-\underline{v}^{1}}{2}+\frac{1-q}{q} \frac{\lambda_{2}}{\lambda_{1}} \frac{\bar{v}^{2}-v^{2}}{2} \\
& \mu_{v^{1} p}^{2}=v^{1}+\frac{1-q}{q} \frac{\lambda_{2}}{\lambda_{1}}\left(v^{2}-\frac{\underline{v}^{2}+\bar{v}^{2}}{2}\right) \\
& \mu_{v^{1} p}^{3}=\mu_{v^{1} p}^{2}+\frac{\bar{v}^{1}-v^{1}}{2}-\frac{1-q}{q} \frac{\lambda_{2}}{\lambda_{1}} \frac{v^{2}-\underline{v}^{2}}{2} \\
& \mu_{v^{2} p}^{1}=\mu_{v^{2} p}^{2}-\frac{\bar{v}^{2}-v^{2}}{2}+\frac{q}{1-q} \frac{\lambda_{1}}{\lambda_{2}} \frac{v^{1}-\underline{v}^{1}}{2} \\
& \mu_{v^{2} p}^{2}=\frac{\underline{v}^{2}+\bar{v}^{2}}{2} \\
& \mu_{v^{2} p}^{3}=\mu_{v^{2} p}^{2}+\frac{v^{2}-\underline{v}^{2}}{2}-\frac{q}{1-q} \frac{\lambda_{1}}{\lambda_{2}} \frac{\bar{v}^{1}-v^{1}}{2},
\end{aligned}
$$

and define

$$
\begin{aligned}
& R_{\lambda}^{1}\left(v^{2}\right)=\left\{v^{1}:\left(v^{1}, v^{2}\right) \in R_{\lambda}^{1}\right\}=\left(\underline{v}^{1}, \underline{v}^{1}+\frac{1-q}{q} \frac{\lambda_{2}}{\lambda_{1}}\left(\bar{v}^{2}-v^{2}\right)\right) \\
& R_{\lambda}^{2}\left(v^{2}\right)=\left\{v^{1}:\left(v^{1}, v^{2}\right) \in R_{\lambda}^{2}\right\}=\left(\underline{v}^{1}+\frac{1-q}{q} \frac{\lambda_{2}}{\lambda_{1}}\left(\bar{v}^{2}-v^{2}\right), \bar{v}^{1}-\frac{1-q}{q} \frac{\lambda_{2}}{\lambda_{1}}\left(v^{2}-\underline{v}^{2}\right)\right) \\
& R_{\lambda}^{3}\left(v^{2}\right)=\left\{v^{1}:\left(v^{1}, v^{2}\right) \in R_{\lambda}^{3}\right\}=\left(\bar{v}^{1}-\frac{1-q}{q} \frac{\lambda_{2}}{\lambda_{1}}\left(v^{2}-\underline{v}^{2}\right), \bar{v}^{1}\right) .
\end{aligned}
$$

We can then write

$$
\Delta^{j}\left(\lambda_{1}, \lambda_{2}\right)=\frac{1}{\bar{v}^{2}-\underline{v}^{2}} \frac{1}{\bar{v}^{1}-\underline{v}^{1}} \frac{1}{2 \bar{c}} \int_{v^{2}}\left[\sum_{k=1}^{3} \int_{R_{\lambda}^{k}\left(v^{2}\right)}\left(v^{j}-E\left[v^{j} \mid p\right]\right)^{2} d v^{1}\right] d v^{2}
$$




\section{Good-1 Producers}

We can write $\Delta^{1}\left(\lambda_{1}, \lambda_{2}\right)$ as

$$
\begin{aligned}
\Delta^{1}\left(\lambda_{1}, \lambda_{2}\right)= & \frac{1}{\bar{v}^{2}-\underline{v}^{2}} \frac{1}{\bar{v}^{1}-\underline{v}^{1}} \frac{1}{2 \bar{c}} \int_{\underline{v}^{2}}^{\bar{v}^{2}}\left[\int_{\underline{v}^{1}}^{\underline{v^{1}+\frac{1-q}{q}} \frac{\lambda_{2}}{\lambda_{1}}\left(\bar{v}^{2}-v^{2}\right)}\left(v^{1}-E\left[v^{1} \mid p\right]\right)^{2} d v^{1}\right] d v^{2} \\
& +\frac{1}{\bar{v}^{2}-\underline{v}^{2}} \frac{1}{\bar{v}^{1}-\underline{v}^{1}} \frac{1}{2 \bar{c}} \int_{\underline{v}^{2}}^{\bar{v}^{2}}\left[\int_{\underline{v}^{1}+\frac{1-q}{q} \frac{\lambda_{2}}{\lambda_{1}}\left(\bar{v}^{2}-v^{2}\right)}^{\bar{v}^{1-\frac{1-q}{q}} \frac{\lambda_{2}}{\lambda_{1}}\left(v^{2}-\underline{v}^{2}\right)}\left(v^{1}-E\left[v^{1} \mid p\right]\right)^{2} d v^{1}\right] d v^{2} \\
& +\frac{1}{\bar{v}^{2}-\underline{v}^{2}} \frac{1}{\bar{v}^{1}-\underline{v}^{1}} \frac{1}{2 \bar{c}} \int_{\underline{v}^{2}}^{\bar{v}^{2}}\left[\int_{\bar{v}^{1}-\frac{1-q}{q} \frac{\lambda_{2}}{\lambda_{1}}\left(v^{2}-\underline{v}^{2}\right)}^{\left.\left.\bar{v}^{1}-E\left[v^{1} \mid p\right]\right)^{2} d v^{1}\right] d v^{2}}\right.
\end{aligned}
$$

Plugging in (7), (8), and (9), the right-hand side becomes

$$
\begin{aligned}
& \frac{1}{\bar{v}^{2}-\underline{v}^{2}} \frac{1}{\bar{v}^{1}-\underline{v}^{1}} \frac{1}{2 \bar{c}} \int_{\underline{v}^{2}}^{\bar{v}^{2}}\left[\int_{\underline{v}^{1}}^{\bar{v}^{1}}\left(\frac{1-q}{q} \frac{\lambda_{2}}{\lambda_{1}}\left(v^{2}-\frac{\underline{v}^{2}+\bar{v}^{2}}{2}\right)\right)^{2} d v^{1}\right] d v^{2} \\
& +\frac{1}{2 \bar{c}} \int_{\underline{v}^{2}}^{\bar{v}^{2}}\left[\int_{\underline{v}^{1}}^{\underline{v}^{1}+\frac{1-q}{q} \frac{\lambda_{2}}{\lambda_{1}}\left(\bar{v}^{2}-v^{2}\right)}\left(\begin{array}{c}
-2\left(\frac{1-q}{q} \frac{\lambda_{2}}{\lambda_{1}}\left(v^{2}-\frac{\underline{\underline{v}}+\bar{v}^{2}}{2}\right)\right) \\
\cdot\left(\frac{v^{1}-\underline{v}^{1}}{2}+\frac{1-q}{q} \frac{\lambda_{2}}{\lambda_{1}} \frac{\bar{v}^{2}-v^{2}}{2}\right) \\
+\left(\frac{\underline{v}^{1}-v^{1}}{2}+\frac{1-q}{q} \frac{\lambda_{2}}{\lambda_{1}} \frac{\bar{v}^{2}-v^{2}}{2}\right)^{2}
\end{array}\right] d F_{v^{1}}\left(v^{1}\right)\right] d F_{v^{2}}\left(v^{2}\right) \\
& +\frac{1}{2 \bar{c}} \int_{\underline{v}^{2}}^{\bar{v}^{2}}\left[\int_{\bar{v}^{1}-\frac{1-q}{q} \frac{\lambda_{2}}{\lambda_{1}}\left(v^{2}-\underline{v}^{2}\right)}^{\bar{v}^{1}}\left(\begin{array}{c}
2\left(\frac{1-q}{q} \frac{\lambda_{2}}{\lambda_{1}}\left(v^{2}-\frac{\underline{v}^{2}+\bar{v}^{2}}{2}\right)\right) \\
\cdot\left(\frac{\bar{v}^{1}-v^{1}}{2}-\frac{1-q}{q} \frac{\lambda_{2}}{\lambda_{1}} \frac{v^{2}-\underline{v}^{2}}{2}\right) \\
+\left(\frac{\bar{v}^{1}-v^{1}}{2}-\frac{1-q}{q} \frac{\lambda_{2}}{\lambda_{1}} \frac{v^{2}-\underline{v}^{2}}{2}\right)^{2}
\end{array}\right] d F_{v^{1}}\left(v^{1}\right)\right] d F_{v^{2}}\left(v^{2}\right)
\end{aligned}
$$

If we substitute $u\left(v^{1}\right)=v^{1}-\underline{v}^{1}$ and $w\left(v^{2}\right)=\bar{v}^{2}-v^{2}$ into the second expression and $u\left(v^{1}\right)=\bar{v}^{1}-v^{1}$ and $w\left(v^{2}\right)=v^{2}-\underline{v}^{2}$ into the third expression, this becomes

$$
\begin{aligned}
\Delta^{1}\left(\lambda_{1}, \lambda_{2}\right) & =\left(\frac{\sigma_{v^{2}}}{\sigma_{v^{1}}} \frac{1-q}{q} \frac{\lambda_{2}}{\lambda_{1}}\right)^{2} \frac{\sigma_{v^{1}}^{2}}{2 \bar{c}}\left(1-\frac{1}{2} \frac{\sigma_{v^{2}}}{\sigma_{v^{1}}} \frac{1-q}{q} \frac{\lambda_{2}}{\lambda_{1}}\right) \\
& =\left(\frac{1}{K\left(\lambda_{1}, \lambda_{2}\right)}\right)^{2} \frac{\sigma_{v^{1}}^{2}}{2 \bar{c}}\left(1-\frac{1}{2} \frac{1}{K\left(\lambda_{1}, \lambda_{2}\right)}\right) .
\end{aligned}
$$




\section{Good-2 Producers}

We can write $\Delta^{2}\left(\lambda_{1}, \lambda_{2}\right)$ as

$$
\begin{aligned}
\Delta^{2}\left(\lambda_{1}, \lambda_{2}\right)= & \frac{1}{\bar{v}^{2}-\underline{v}^{2}} \frac{1}{\bar{v}^{1}-\underline{v}^{1}} \frac{1}{2 \bar{c}} \int_{\underline{v}^{2}}^{\bar{v}^{2}}\left[\int_{\underline{v}^{1}}^{\underline{v^{1}+\frac{1-q}{q}} \frac{\lambda_{2}}{\lambda_{1}}\left(\bar{v}^{2}-v^{2}\right)}\left(v^{2}-E\left[v^{2} \mid p\right]\right)^{2} d v^{1}\right] d v^{2} \\
& +\frac{1}{\bar{v}^{2}-\underline{v}^{2}} \frac{1}{\bar{v}^{1}-\underline{v}^{1}} \frac{1}{2 \bar{c}} \int_{\underline{v}^{2}}^{\bar{v}^{2}}\left[\int_{\underline{v}^{1}+\frac{1-q}{q} \frac{\lambda_{2}}{\lambda_{1}}\left(\bar{v}^{2}-v^{2}\right)}^{\bar{v}^{1}-\frac{1-q}{q} \frac{\lambda_{2}}{\lambda_{1}}\left(v^{2}-\underline{v}^{2}\right)}\left(v^{2}-E\left[v^{2} \mid p\right]\right)^{2} d v^{1}\right] d v^{2} \\
& +\frac{1}{\bar{v}^{2}-\underline{v}^{2}} \frac{1}{\bar{v}^{1}-\underline{v}^{1}} \frac{1}{2 \bar{c}} \int_{\underline{v}^{2}}^{\bar{v}^{2}}\left[\int_{\bar{v}^{1}-\frac{1-q}{q} \frac{\lambda_{2}}{\lambda_{1}}\left(v^{2}-\underline{v}^{2}\right)}^{\left.\left.\bar{v}^{1}-E\left[v^{2} \mid p\right]\right)^{2} d v^{1}\right] d v^{2}}\right.
\end{aligned}
$$

Plugging in (10), (11), and (12), the right-hand side becomes

$$
\begin{aligned}
& \frac{1}{\bar{v}^{2}-\underline{v}^{2}} \frac{1}{\bar{v}^{1}-\underline{v}^{1}} \frac{1}{2 \bar{c}} \int_{\underline{v}^{2}}^{\bar{v}^{2}}\left[\int_{\underline{v}^{1}}^{\bar{v}^{1}}\left(v^{2}-\frac{\underline{v}^{2}+\bar{v}^{2}}{2}\right)^{2} d v^{1}\right] d v^{2} \\
& +\frac{1}{2 \bar{c}} \int_{\underline{v}^{2}}^{\bar{v}^{2}}\left[\int_{\underline{v}^{1}}^{\underline{v}^{1}+\frac{1-q}{q} \frac{\lambda_{2}}{\lambda_{1}}\left(\bar{v}^{2}-v^{2}\right)}\left(\begin{array}{c}
2\left(v^{2}-\frac{\underline{v}^{2}+\bar{v}^{2}}{2}\right) \\
\cdot\left(\frac{\bar{v}^{2}-v^{2}}{2}-\frac{q}{1-q} \frac{\lambda_{1}}{\lambda_{2}} \frac{v^{1}-\underline{v}^{1}}{2}\right) \\
+\left(\frac{\bar{v}^{2}-v^{2}}{2}-\frac{q}{1-q} \frac{\lambda_{1}}{\lambda_{2}} \frac{v^{1}-\underline{v}^{1}}{2}\right)^{2}
\end{array}\right) d F_{v^{1}}\left(v^{1}\right)\right] d F_{v^{2}}\left(v^{2}\right) \\
& +\frac{1}{2 \bar{c}} \int_{\underline{v}^{2}}^{\bar{v}^{2}}\left[\int_{\bar{v}^{1}-\frac{1-q}{q} \frac{\lambda_{2}}{\lambda_{1}}\left(v^{2}-\underline{v}^{2}\right)}^{\bar{v}^{1}}\left(\begin{array}{c}
-2\left(v^{2}-\frac{\underline{v}^{2}+\bar{v}^{2}}{2}\right) \\
\cdot\left(\frac{v^{2}-\underline{v}^{2}}{2}-\frac{q}{1-q} \frac{\lambda_{1}}{\lambda_{2}} \frac{\bar{v}^{1}-v^{1}}{2}\right) \\
+\left(\frac{v^{2}-\underline{v}^{2}}{2}-\frac{q}{1-q} \frac{\lambda_{1}}{\lambda_{2}} \frac{\bar{v}^{1}-v^{1}}{2}\right)^{2}
\end{array}\right] d F_{v^{1}}\left(v^{1}\right)\right] d F_{v^{2}}\left(v^{2}\right)
\end{aligned}
$$

If we substitute $u\left(v^{1}\right)=v^{1}-\underline{v}^{1}$ and $w\left(v^{2}\right)=\bar{v}^{2}-v^{2}$ into the second expression and $u\left(v^{1}\right)=\bar{v}^{1}-v^{1}$ and $w\left(v^{2}\right)=v^{2}-\underline{v}^{2}$ into the third expression, this becomes 


$$
\begin{aligned}
& \Delta^{2}\left(\lambda_{1}, \lambda_{2}\right)=\frac{\sigma_{v^{2}}^{2}}{2 \bar{c}}+2 \frac{1}{\bar{v}^{2}-\underline{v}^{2}} \frac{1}{\bar{v}^{1}-\underline{v}^{1}} \frac{1}{2 \bar{c}} \int_{0}^{\bar{v}^{2}-\underline{v}^{2}}\left[\int_{0}^{\frac{1-q}{q} \frac{\lambda_{2}}{\lambda_{1}} w}\left(\begin{array}{c}
\left(-w+\frac{\bar{v}^{2}-\underline{v}^{2}}{2}\right) \\
\cdot\left(w-\frac{q}{1-q} \frac{\lambda_{1}}{\lambda_{2}} u\right) \\
+\left(\frac{w}{2}-\frac{q}{1-q} \frac{\lambda_{1}}{\lambda_{2}} \frac{u}{2}\right)^{2}
\end{array}\right] d u\right] d w \\
& =\frac{\sigma_{v^{2}}^{2}}{2 \bar{c}}\left(1-\frac{1}{2} \frac{\sigma_{v^{2}}}{\sigma_{v^{1}}} \frac{1-q}{q} \frac{\lambda_{2}}{\lambda_{1}}\right) \\
& =\frac{\sigma_{v^{2}}^{2}}{2 \bar{c}}\left(1-\frac{1}{2} \frac{1}{K\left(\lambda_{1}, \lambda_{2}\right)}\right)
\end{aligned}
$$

\subsubsection{Case B}

The derivations of $\Delta^{1}\left(\lambda_{1}, \lambda_{2}\right)$ and $\Delta^{2}\left(\lambda_{1}, \lambda_{2}\right)$ for the case where case B obtains are similar to case A.

\subsection{Proofs of Lemmas}

Proof of Lemma 1. Note that for a fixed $\lambda_{1}>0$, as $\lambda_{2} \rightarrow 0, K\left(\lambda_{1}, \lambda_{2}\right) \rightarrow+\infty$. Fix $\lambda_{1}$. Then for $\lambda_{2} \leq \frac{q}{1-q} \lambda_{1} \frac{\sigma_{v^{1}}}{\sigma_{v^{2}}}$, we have that $K\left(\lambda_{1}, \lambda_{2}\right) \geq 1$, so that

$$
\Delta^{1}\left(\lambda_{1}, \lambda_{2}\right)=\left(\frac{1-q}{q} \frac{\lambda_{2}}{\lambda_{1}} \frac{\sigma_{v^{2}}}{\sigma_{v^{1}}}\right)^{2} \frac{\sigma_{v^{1}}^{2}}{2 \bar{c}}\left(1-\frac{1}{2} \frac{1-q}{q} \frac{\lambda_{2}}{\lambda_{1}} \frac{\sigma_{v^{2}}}{\sigma_{v^{1}}}\right)
$$

and thus $\Delta^{1}\left(\lambda_{1}, 0\right)=0$ for $\lambda_{1}>0$, so $\Delta^{1}\left(\lambda_{1}, 0\right)-\bar{k} \lambda_{1}<0$ for all $\lambda_{1}>0$. Therefore, $\lim _{\lambda_{2} \downarrow 0} \lambda_{1}^{*}\left(\lambda_{2}\right)=0$. A similar argument establishes that $\lim _{\lambda_{1} \downarrow 0} \lambda_{2}^{*}\left(\lambda_{1}\right)=0$.

Proof of Lemma 2. This follows directly from the fact that $\Delta^{1}\left(\lambda_{1}, \lambda_{2}\right)$ is increasing in $\lambda_{2}$.

Proof of Lemma 3. Suppose that $\lambda_{2}^{n} \rightarrow 0$, and assume $\lambda_{2}^{n} \leq \frac{q}{1-q} \lambda_{1}^{*}\left(\lambda_{2}^{n}\right) \frac{\sigma_{v^{1}}}{\sigma_{v^{2}}}$ for all $n$. Note that $\lambda_{1}^{*}\left(\lambda_{2}^{n}\right)$ solves

$$
\left(\frac{1-q}{q} \frac{\lambda_{2}}{\lambda_{1}^{*}\left(\lambda_{2}^{n}\right)} \frac{\sigma_{v^{2}}}{\sigma_{v^{1}}}\right)^{2} \frac{\sigma_{v^{1}}^{2}}{2 \bar{c}}\left(1-\frac{1}{2} \frac{1-q}{q} \frac{\lambda_{2}}{\lambda_{1}^{*}\left(\lambda_{2}^{n}\right)} \frac{\sigma_{v^{2}}}{\sigma_{v^{1}}}\right)=\bar{k} \lambda_{1}^{*}\left(\lambda_{2}^{n}\right)
$$


Assume $\frac{\lambda_{2}^{n}}{\lambda_{1}^{*}\left(\lambda_{2}^{n}\right)} \rightarrow+\infty$. We have that in the limit, the left-hand side is infinite and the right-hand side is 0 , which is a contradiction, so $\lambda_{1}^{*}\left(\lambda_{2}^{n}\right)$ cannot converge to zero at a faster rate than $\lambda_{2}^{n}$. Next, suppose $\frac{\lambda_{2}^{n}}{\lambda_{1}^{n}\left(\lambda_{2}^{n}\right)} \rightarrow \alpha \leq \frac{q}{1-q} \frac{\sigma_{v 1}}{\sigma_{v^{2}}}$. Then, in the limit, this becomes

$$
\left(\frac{1-q}{q} \alpha \frac{\sigma_{v^{2}}}{\sigma_{v^{1}}}\right)^{2} \frac{\sigma_{v^{1}}^{2}}{2 \bar{c}}\left(1-\frac{1}{2} \frac{1-q}{q} \alpha \frac{\sigma_{v^{2}}}{\sigma_{v^{1}}}\right)=0,
$$

which holds only if $\alpha=2 \frac{q}{1-q} \frac{\sigma_{v 1}}{\sigma_{v^{2}}}$, which contradicts $\alpha \leq \frac{q}{1-q} \frac{\sigma_{v^{1}}}{\sigma_{v^{2}}}$. Suppose $\frac{\lambda_{2}^{n}}{\lambda_{1}^{*}\left(\lambda_{2}^{n}\right)} \rightarrow \alpha>$ $\frac{q}{1-q} \frac{\sigma_{v 1}}{\sigma_{v^{2}}}$. Then, in the limit, this becomes

$$
\frac{\sigma_{v^{1}}^{2}}{2 \bar{c}}\left(1-\frac{1}{2} \frac{q}{1-q} \frac{1}{\alpha} \frac{\sigma_{v^{1}}}{\sigma_{v^{2}}}\right)=0
$$

which holds only if $\alpha=\frac{1}{2} \frac{q}{1-q} \frac{\sigma_{v 1}}{\sigma_{v^{2}}}$. Thus, it must be the case that $\frac{\lambda_{2}^{n}}{\lambda_{1}^{*}\left(\lambda_{2}^{n}\right)}=0$, which establishes that $\lim _{\lambda_{2} \rightarrow 0} \frac{\lambda_{1}^{*}\left(\lambda_{2}\right)}{\lambda_{2}}=+\infty$, so that the slope of the group best-response function is infinite at the origin. A similar argument establishes that $\lim _{\lambda_{1} \rightarrow 0} \frac{\lambda_{2}^{*}\left(\lambda_{1}\right)}{\lambda_{1}}=+\infty$.

Proof of Lemma 4. For $K\left(\lambda_{1}, \lambda_{2}\right) \geq 1, \lambda_{1}^{*}\left(\lambda_{2}\right)$ implicitly solves

$$
\left(\frac{1-q}{q} \frac{\lambda_{2}}{\lambda_{1}^{*}\left(\lambda_{2}\right)} \frac{\sigma_{v^{2}}}{\sigma_{v^{1}}}\right)^{2} \frac{\sigma_{v^{1}}^{2}}{2 \bar{c}}\left(1-\frac{1}{2} \frac{1-q}{q} \frac{\lambda_{2}}{\lambda_{1}^{*}\left(\lambda_{2}\right)} \frac{\sigma_{v^{2}}}{\sigma_{v^{1}}}\right)=\bar{k} \lambda_{1}^{*}\left(\lambda_{2}\right)
$$

$\lambda_{1}^{*}\left(\lambda_{2}\right)$ is concave in $\lambda_{2}$ if $\frac{\lambda_{1}^{*}\left(\lambda_{2}\right)}{\lambda_{2}}$ is decreasing in $\lambda_{2}$. or if $\frac{\lambda_{2}}{\lambda_{1}^{*}\left(\lambda_{2}\right)}$ is increasing in $\lambda_{2}$. Implicitly differentiating with respect to $\lambda_{2}$ gives us

$$
\frac{d}{d \lambda_{2}}\left(\frac{\lambda_{2}}{\lambda_{1}^{*}\left(\lambda_{2}\right)}\right)=\frac{\bar{k}\left(\frac{\lambda_{2}}{\lambda_{1}^{*}\left(\lambda_{2}\right)}\right)}{\frac{3}{2}\left(\frac{1-q}{q} \frac{\sigma_{v^{2}}}{\sigma_{v 1}}\right)^{2}\left(\frac{\lambda_{2}}{\lambda_{1}^{*}\left(\lambda_{2}\right)}\right)^{3} \frac{\sigma_{v 1}^{2}}{2 \bar{c}}\left(\frac{4}{3}-\frac{1}{K\left(\lambda_{1}, \lambda_{2}\right)}\right)+\bar{k} \lambda_{2}}
$$

which is positive, since $K\left(\lambda_{1}, \lambda_{2}\right) \geq 1$. Thus, $\lambda_{1}^{*}\left(\lambda_{2}\right)$ is concave in this region. For $K\left(\lambda_{1}, \lambda_{2}\right)<1, \lambda_{1}^{*}\left(\lambda_{2}\right)$ is given by

$$
\lambda_{1}^{*}\left(\lambda_{2}\right)=\frac{\frac{\sigma_{v 1}^{2}}{2 \bar{c}}}{\bar{k}+\frac{\sigma_{v 1}^{2}}{2 \bar{c}} \frac{1}{2} \frac{q}{1-q} \frac{1}{\lambda_{2}} \frac{\sigma_{v 1}}{\sigma_{v^{2}}}},
$$


so that

$$
\frac{d}{d \lambda_{2}}\left(\frac{\lambda_{2}}{\lambda_{1}^{*}\left(\lambda_{2}\right)}\right)=\frac{\bar{k}}{\frac{\sigma_{v^{1}}^{2}}{2 \bar{c}}},
$$

which is also positive. Thus, in this region, $\lambda_{1}^{*}\left(\lambda_{2}\right)$ is concave. Finally, it is algebraically intensive, but easy to show that $\frac{\lambda_{2}}{\lambda_{1}^{*}\left(\lambda_{2}\right)}$ is increasing across the $K\left(\lambda_{1}, \lambda_{2}\right)=1$ boundary. Since $\lambda_{1}^{*}\left(\lambda_{2}\right)$ is continuous in $\lambda_{2}$ for all $\lambda_{2}>0$, we have that $\lambda_{1}^{*}\left(\lambda_{2}\right)$ is globally concave on $(0,1]$. A similar argument establishes that $\lambda_{2}^{*}\left(\lambda_{1}\right)$ is globally concave on $(0,1]$ as well. 